\title{
Envolvimento Paterno com Filhos Adotivos e a Estrutura Familiar
}

\author{
Rovana Kinas Bueno ${ }^{1}$ \\ Mauro Luís Vieira \\ Maria Aparecida Crepaldi \\ Universidade Federal de Santa Catarina
}

\begin{abstract}
RESUMO: O presente artigo teve como objetivo analisar a relação entre envolvimento paterno com filhos adotivos e estrutura familiar. Participaram do estudo quatro pais de crianças que foram adotadas até um ano de idade. Esta pesquisa qualitativa teve como instrumentos um questionário sociodemográfico e duas entrevistas semiestruturadas. Constata-se que esses pais brincam, cuidam, conversam, demonstram afeto e têm lazer com seus filhos. Eles também buscam ser participativos quando estão disponíveis, dividindo tarefas e responsabilidades com suas esposas, destacando-se seu papel de provedor. No que se refere à estrutura familiar, predominam nas famílias o relacionamento harmônico ou muito estreito. Conclui-se que, nas famílias investigadas, os pais mostraram-se envolvidos com seus filhos.
\end{abstract}

Palavras-chave: paternidade, adoção, relações pai-filho, relações familiares

\section{Father Involvement with Adopted Children and the Family Structure}

\begin{abstract}
The present article aimed to analyze the relationship between father involvement with adopted children and family structure. Participated four fathers of children who were adopted until a year old. This qualitative research used as instruments a questionnaire and two semistructured interviews. It is verified that these fathers play, take care, talk, show affection and have leisure with their children. They also seek to be participants when they are available, and share some tasks and responsibilities with their wives, highlighting their role as providers of financial support. Concerning the family structure, harmonic or too narrow relationships predominate in the families. It is concluded that, in investigated families, fathers get involved with their children.
\end{abstract}

Keywords: paternity, adoption, father-child relations, family relations

Constata-se uma intensificação no envolvimento do pai com seus filhos nos últimos anos (Vieira et al., 2013). Esse maior envolvimento paterno repercute positivamente no desenvolvimento da criança (Bueno, Gomes, \& Crepaldi, 2015). No entanto, uma questão que surge a partir desses dados é o que é envolvimento paterno? Existem diferentes definições para esse conceito. No presente artigo, adota-se a definição de Lamb, Pleck, Charnov e Levine (1985), que parece abarcar dimensões fundamentais que caracterizam o constructo. Os autores mencionados definem o envolvimento paterno por meio de três dimensões: Interação, Disponibilidade e Responsabilidade. A interação se refere ao contato direto do pai com seu filho no compartilhamento de atividades e brincadeiras. A disponibilidade diz respeito ao potencial de acessibilidade física e psicológica do pai para a interação, em virtude de estar presente ou acessível para o filho. A responsabilidade é o papel que o pai assume em garantir cuidados à criança, disponibilizando-se e providenciando recursos (Lamb, 1997).

1 Endereço para correspondência: Nepedi, Programa de Pós-Graduação em Psicologia, Universidade Federal de Santa Catarina, Campus Universitário Reitor João David Ferreira Lima, Trindade, Florianópolis, SC, Brasil. CEP: 88.040-900 E-mail: rovanak@gmail.com
O envolvimento paterno geralmente é investigado por meio de estudos com pais biológicos (Vieira et al., 2014). Contudo, há os casais que desejam ter filhos, mas biologicamente não conseguem. Muitos desses casais recorrem a técnicas de reprodução assistida para tentar gerar filhos biológicos e/ou optam por adotar uma criança. Embora muitos casais que adotam já possuam filhos biológicos, a maioria dos adotantes $(76,19 \%)$ tem como principal motivação a impossibilidade ou dificuldade em gerar filhos biológicos (Weber, 2003). Assim, o ato de adotar surge como uma das possibilidades que o homem possui para tornar-se pai (Andrade, Costa, \& Rossetti-Ferreira, 2006; Ghirardi, 2009).

Em uma revisão sistemática realizada sobre a paternidade no Brasil considerando estudos empíricos (Vieira et al., 2014), constatou-se que apenas $3 \%$ das obras se referiam ao processo de adoção e à tentativa dos pais em superar a falta dos laços consanguíneos por meio do fortalecimento dos laços afetivos. Mesmo nesses artigos, constatou-se a prevalência de um maior envolvimento materno, ficando os pais com o papel de "ajudantes" da mãe e responsáveis, prioritariamente, pelo sustento econômico da família.

Essa “organização familiar" e o modo como os membros da família interagem são fatores que influenciam o envolvimento paterno. A família pode ser compreendida como 
um sistema composto por subsistemas (parental, conjugal, entre outros) que são interdependentes. Os subsistemas são transpassados por fronteiras (limites abstratos que variam conforme sua permeabilidade) e são utilizados para definir a estrutura familiar, a qual é o conjunto invisível de exigências funcionais que organizam o modo pelo qual os membros da família interagem ao longo do tempo (Minuchin, 1982).

É importante esclarecer que, embora exista a definição de estrutura familiar, não se classificam as famílias em estruturadas ou desestruturadas, mas em famílias funcionais ou disfuncionais (Minuchin, 1982). As famílias funcionais são aquelas que possuem um funcionamento sistêmico pautado em relacionamentos harmônicos (Wendt \& Crepaldi, 2008) e, consequentemente, apresentam mais facilidades para enfrentar os estressores do ciclo de vida. Um dos motivos para essa mudança conceitual (de estruturada para funcional) é devido à diversidade de configurações familiares que existe na atualidade e que acaba sendo confundida com o conceito de estrutura familiar. Mantém-se o conceito de estrutura familiar (Minuchin, 1982), por ser um conceito atual, útil e abrangente, ou seja, por se referir a padrões de interação que definem como, quando e com quem as pessoas se relacionam.

Esses padrões de interação são denominados de padrões transacionais, os quais podem ser: Relacionamento harmônico (refere-se à experiência emocional de união entre membros da família, que, diferenciados, sustentam sentimentos positivos um para com o outro e que possuem interesses, atitudes ou valores recíprocos); Relacionamento muito estreito ou superenvolvimento (no qual não há diferenciação entre os membros, logo se verifica dependência emocional); Relacionamento fundido e conflitual (no qual existe estreita dependência emocional e conflitos constantes entre os membros familiares, não havendo diferenciação entre os mesmos); Aliança (refere-se a uma ligação baseada nas lealdades que interferem, também, no processo de diferenciação); Relacionamento conflituoso (no qual há atritos constantes que ocasionam ansiedades e desavenças trazidas pela dificuldade de comunicação); Relacionamento vulnerável (no qual não há conflito explícito, mas o mesmo pode ocorrer em situações adversas); Relacionamento distante (no qual há pouco contato principalmente de ordem emocional, comum em famílias com fronteiras rígidas); Rompimento (no qual, embora se mantenha uma ligação emocional, não há contato entre os membros); Triangulação (é a configuração emocional de três pessoas, na qual a pessoa triangulada alivia a tensão da díade, assim, em situação de ausência de conflito explícito, apresenta insegurança ou sofrimento emocional, e, quando o conflito é explícito pela díade, a pessoa triangulada encontra-se aliviada); Coalizão (é a aliança de duas pessoas contra uma terceira) (Wendt \& Crepaldi, 2008). Assim, diferentes estruturas familiares se associam a diferentes padrões transacionais que influenciarão o envolvimento paterno.

Em termos de relevância social, este estudo contribui para o aprofundamento do conhecimento sobre o envolvimento paterno, o que pode colaborar para que o pai possa desempenhar ainda melhor sua função, principalmente no caso de adoção, que é um fenômeno complexo. A compreensão das relações entre envolvimento paterno com filhos adotivos e a estrutura familiar facilitará futuras intervenções no que se refere às relações familiares, visto que possibilita a identificação de características familiares nas quais o pai demonstra maior envolvimento com seus filhos.

Do ponto de vista científico, a produção nacional sobre o envolvimento paterno com filhos adotivos e a estrutura familiar ainda é reduzida. Realizou-se uma busca no mês de novembro de 2013 nos portais Scielo e Pepsic e na base de dados Index Psi (periódicos) utilizando a combinação de descritores paternidade, adoção e relações familiares. Não se encontraram obras que envolvam esses três descritores. Assim, esse estudo é relevante, pois contribui para o avanço do conhecimento científico.

Diante do exposto e da relevância do tema apresentado, propôs-se como objetivo geral do presente trabalho analisar a relação entre o envolvimento paterno com filhos adotivos e a estrutura familiar. Como objetivos específicos têm-se: (a) Caracterizar o envolvimento de pais com filhos adotivos, em termos de interação, disponibilidade e responsabilidade; (b) Relacionar o envolvimento paterno com filhos adotivos e os padrões de interação da família; (c) Relacionar o envolvimento paterno com filhos adotivos e a configuração familiar. Para melhor compreensão dos fenômenos, utilizouse a epistemologia sistêmica (Vasconcellos, 2010), por ser uma perspectiva que considera o desenvolvimento dos seres humanos em contextos.

\section{Método}

\section{Caracterização da Pesquisa}

Esta pesquisa constitui-se em um estudo qualitativo, do tipo transversal. Quanto aos objetivos, este estudo é do tipo exploratório e descritivo (Sampieri, Collado, \& Lucio, 2006).

\section{Participantes}

Participaram da pesquisa quatro pais (homens), os quais foram acessados em duas instituições escolhidas por critério de intencionalidade. Essas instituições são de uma cidade do sul do Brasil, a qual foi escolhida por acessibilidade (Sampieri et al., 2006). Os critérios de inclusão foram ter um filho adotivo com três ou quatro anos de idade e ter adotado seu filho(a) quando este tinha menos de um ano de idade. O critério de exclusão era a criança ou o pai apresentar alguma deficiência. Todos os pais entrevistados decidiram pela adoção após não conseguirem ter filhos biológicos. Cada família foi identificada com um número, assim, o primeiro pai apresentado é denominado P01, seu filho é F01, sua esposa E01. O segundo pai é o P02, e assim sucessivamente. A Tabela 1 apresenta as características sociodemográficas dos participantes.

\section{Aspectos Éticos}

A pesquisa foi desenvolvida com base em parâmetros éticos, atendendo à Resolução $\mathrm{n}^{\circ} 196$, de 10 de outubro 
de 1996, do Conselho Nacional de Saúde (CNS), a qual estava em vigor no momento da elaboração da presente pesquisa. Este projeto foi aprovado pelo Comitê de Ética em Pesquisa com Seres Humanos (CEPSH), sob o Parecer Consubstanciado 216.414, no dia 18 de fevereiro de 2013.
Envolvimento Paterno. Por fim, após esta, realizou-se a Entrevista Semiestruturada de Genograma. A coleta de dados teve duração aproximada de uma hora e meia com cada pai. As entrevistas foram gravadas com o consentimento dos participantes e transcritas, posteriormente, na íntegra.

Tabela 1. Caracterização sociodemográfica dos participantes

\begin{tabular}{|c|c|c|c|c|c|c|}
\hline Caso & $\begin{array}{c}\text { Membros } \\
\text { da Família }\end{array}$ & Idade & Escolaridade & Profissão & $\begin{array}{c}\text { Jornada de } \\
\text { trabalho semanal }\end{array}$ & Tempo de União \\
\hline \multirow{3}{*}{1} & Pai & 37 anos & Ensino Superior & Servidor público & $40 \mathrm{~h}$ & \\
\hline & Mãe & 37 anos & Ensino Médio & Do lar & - & 11 \\
\hline & Filho & 3 anos e 1 mês & - & - & - & \\
\hline \multirow{3}{*}{2} & Pai & 50 anos & Ensino Superior & Corretor de imóveis & $16 \mathrm{~h} *$ & \\
\hline & Mãe & 47 anos & Ensino Médio & Do lar & - & 19 \\
\hline & Filha & 3 anos e 7 meses & - & - & - & \\
\hline \multirow{3}{*}{3} & Pai & 53 anos & Pós-Graduação & Médico & $40 \mathrm{~h}$ ou mais & \\
\hline & Mãe & 53 anos & Pós-Graduação & Professora universitária & $40 \mathrm{~h}$ ou mais & 30 \\
\hline & Filho & 4 anos e 6 meses & - & - & - & \\
\hline \multirow{3}{*}{4} & Pai & 37 anos & Ensino Médio & Vigilante & $36 \mathrm{~h} * *$ & \\
\hline & Mãe & 39 anos & Ensino Médio & Do lar/Diarista & $16 \mathrm{~h}^{*}$ & 13 \\
\hline & & 4 anos e 11 meses & - & - & - & \\
\hline
\end{tabular}

Notas. * Aproximadamente; ** Turno noturno

\section{Instrumentos}

Para a realização do presente estudo, foram utilizados três instrumentos, que são descritos brevemente a seguir.

a) Questionário Sociodemográfico: Desenvolvido por pesquisadores do Núcleo de Estudos e Pesquisa em Desenvolvimento Infantil (NEPeDI) e adaptado para a presente pesquisa, possui perguntas que se referem basicamente aos dados da família e à renda familiar;

b) Entrevista Semiestruturada de Envolvimento Paterno: Elaborada para a presente pesquisa e explorou o envolvimento paterno;

c) Entrevista Semiestruturada de Genograma: Elaborada para a presente pesquisa, foi utilizada para a construção do genograma (representação gráfica da família, em que se pode incluir informações como os padrões de relacionamento) juntamente com o participante, explorando a estrutura familiar. As definições dos símbolos e padrões relacionais foram ancorados na literatura (McGoldrick \& Gerson, 1995; Wendt \& Crepaldi, 2008).

\section{Procedimentos para Coleta de Dados}

Após a aprovação do projeto pelo CEPSH, realizou-se uma entrevista preliminar com um pai adotivo, recrutado por acessibilidade, com o objetivo de aprimorar os instrumentos. Após, agendou-se a coleta de dados com os quatro pais acessados através das instituições. Para a coleta, após leitura e assinatura do Termo de Consentimento Livre e Esclarecido (TCLE), o pai respondeu o Questionário Sociodemográfico e, então, realizou-se a Entrevista Semiestruturada de

\section{Análise de Dados}

Os dados obtidos com o Questionário Sociodemográfico foram submetidos à análise estatística descritiva. A Entrevista Semiestruturada de Envolvimento Paterno foi analisada conforme seu conteúdo (Bardin, 1977), utilizando-se o software ATLAS.ti 5.1 para organização dos dados, dos quais emergiram as seguintes categorias temáticas: Interação, Disponibilidade e Responsabilidade. Os dados obtidos por meio da Entrevista Semiestruturada de Genograma e da confecção do mesmo foram analisados gráfica e clinicamente (Wendt, 2006). A descrição dos padrões de interação foi agrupada na categoria denominada Padrões de relacionamento.

Os sistemas de categorias constituídos no processo de análise, as entrevistas e o genograma foram submetidos separadamente a duas juízas: duas psicólogas terapeutas relacionais sistêmicas. A concordância de cada uma delas com a pesquisadora foi de $90 \%$ no que se refere às categorias que emergiram na análise de conteúdo e $95 \%$ na classificação dos padrões de relacionamento familiar. A equação para calcular a concordância foi a avaliação de fidedignidade utilizada nas observações (Fagundes, 1999), que resulta do número de acordos da juíza dividido pelo número de acordos da juíza somados ao número de desacordos dessa juíza. O resultado é multiplicado por 100 para resultar em uma percentagem.

\section{Resultados}

Serão descritas, a seguir, as categorias: Interação, Disponibilidade, Responsabilidade e Padrões de relacionamento. A categoria Interação abarca o que o pai faz com a criança quando está com ela. Verifica-se que o pai cuida do filho, conversa, demonstra afeto, brinca e possui 
momentos de lazer com o mesmo. Cada uma dessas temáticas refere-se a uma subcategoria.

A subcategoria cuidar representa os cuidados que o pai presta à criança. Embora os pais se mostrem participativos, os cuidados mencionados pelos pais - como fazer a mamadeira (P01, P02, P03 e P04), trocar a fralda (P01, P02 e P03), fazer dormir (P01, P02 e P03), dar banho (P01, P03 e P04), vestir o filho (P01 e P04), dar a comida (P02 e P03) -, não são realizados exclusivamente por eles. P02 afirma: "Eu fico muito tempo com a [filha], mas a higiene da [filha], a alimentação da [filha], é tudo com minha mulher". Além disso, dois pais (P01 e P03) ressaltam que buscam tomar a iniciativa desses cuidados.

Ao serem questionados como aprenderam a cuidar de criança, três pais (P02, P03 e P04) afirmaram que foi através da convivência com outras crianças, apenas um (P01) contou que foi com seu próprio filho, com auxílio da esposa. Do mesmo modo, três pais (P01, P03 e P04) afirmaram que sua esposa lhes ajuda a se envolver com o filho, embora P02 tenha alegado que não há interferência da mesma.

A subcategoria conversar refere-se ao que o pai conversa com o filho. A fala de $\mathrm{P} 01$ retrata esse conversar:

A conversa nossa gira em torno de escola, geralmente é uma conversa bem lúdica, de brincadeiras (...) conversa sobre os brinquedos, conversa sobre a escola, sobre as atitudes dele também eu converso com ele, ontem, por exemplo, eu fiquei chateado porque a professora me disse que ele bateu nos amigos, ai eu conversei com ele, deixei ele de disciplina, ai eu conversei com ele sobre isso.

Os pais afirmam que costumam conversar com seus filhos sobre a escola e também sobre a brincadeira, no momento em que esta acontece. O conversar também é aproveitado para os pais ensinarem e explicarem coisas aos filhos, bem como para disciplinar. Assim, verificam-se diferentes usos e funções da conversa na relação pai-filho.

Destaca-se que o conversar também é utilizado para contar ao filho sobre a adoção. P01, P02 e P03 relatam que estão contando aos poucos e de modo indireto, até que o filho tenha maior compreensão. Esse contar indireto é evidenciado por P01, que fala para seu filho: "todas as crianças nascem da barriga da mamãe, mas o [criança] nasceu do coração da mãe, o coração da mãe cresceu".

A subcategoria demonstrar afeto retrata o carinho que os pais sentem e expressam aos seus filhos. Todos os pais afirmam que buscam demonstrar o afeto que sentem pelo filho. P01 exemplifica esse fato: "Ai às vezes ela [esposa] arruma ele [filho], muitas vezes eu arrumo, o bichinho precisa de muita balda sozinho, então tem que ir lá, tem que fazer o chamego, devagarinho e tal".

A subcategoria brincar se refere às brincadeiras que os pais realizam com seus filhos. $\mathrm{O}$ brincar, de modo geral, foi mencionado por todos os pais e, não considerando o tipo de brincadeira, foi a subcategoria com maior frequência de ocorrência. Além do brincar em geral, dos tipos específicos de brincar, ganhou destaque o andar de bicicleta e ver desenho com o filho na televisão (TV). Jogar bola (P01, P02 e P03) e ir ao parque (P01, P03 e P04) foi mencionado por três de quatro pais. Embora, às vezes, o pai apenas queira supervisionar o brincar do filho (como mencionado por P03 e P04), a fala de P04 evidencia que, muitas vezes, isso não é possível:
Não, brinca junto, porque ela vai lá no tanque pra pegar água, pra fazer bolinho, ai tem que fazer, pra fazer café, eu tenho que estar comendo junto se não ela já grita, "ô pai, tem que tá junto!!!” tem que estar igual, porque causa do carro [na rua] e tudo e tem que estar participando ali junto também. (P04)

A subcategoria lazer abarca os momentos de entretenimento. Os pais citam como lazer o sair de casa em família. Ao especificarem esse sair de casa, evidenciam-se o passear (P04 e P04) e o visitar os familiares (P01 e P04), bem como ir à praia (P02), ao shopping $(\mathrm{P} 01)$ e ao teatro $(\mathrm{P} 01)$. O lazer é exemplificado na fala de P04: "E final de semana, tipo sábado ou domingo que a gente costuma passear, ela [filha] está junto também".

Assim, na categoria Disponibilidade, que se refere à acessibilidade de tempo do pai para estar com o filho, verificase a influência do trabalho do pai no tempo em que os pais ficam disponíveis para o filho. Tem-se como subcategorias: Trabalho e Participativo.

A subcategoria trabalho diz respeito ao trabalho do pai. Os dois pais (P02 e P04) que possuem uma carga horária de trabalho mais flexível conseguem passar mais tempo com seus filhos. P01 relata essa questão da carga horária: " $A$ participação pra mim é, eu acho que eu não poderia assim, só se eu não trabalhasse, se eu não trabalhasse eu poderia participar melhor, mais da vida dele". Ressalta-se também que, nas quatro famílias, o trabalho do pai (turno e carga horária) organiza a rotina familiar:

Quando eu não trabalho, a gente acorda junto. (...) Quando eu trabalho, minha esposa já deixa ela arrumadinha pra não perder muito tempo (...) aí já deixa ela pronta e já levo. E quando eu folgo, eu arrumo mesmo, até porque tem dias que a minha esposa trabalha, então eu ajeito tudo. (P04)

A subcategoria participativo evidencia que, no momento em que os pais não estão trabalhando e estão disponíveis para os filhos, eles costumam ser participativos. Ressalta-se que o interagir com o filho remete à categoria interação, mas mantém-se essa subcategoria na categoria disponibilidade por se referir à percepção que os pais possuem do tempo que estão disponíveis aos seus filhos, o que inclui participar da vida do filho (interação) ou participar das tarefas da casa. Isso é reforçado pela fala de P03:

Dá pra dizer que hoje eu vivo em função dele. Eu digo, eu falo brincando que hoje eu faço duas coisas, eu trabalho, se eu não estou trabalhando, eu estou cuidando do [filho], se eu não estou cuidando do [filho], eu estou trabalhando, claro que às vezes tem alguns momentos que eu faço alguma coisa de lazer que ele não está junto (...). Praticamente sempre, até nos meus momentos de lazer eu estou sempre com ele.

A categoria Responsabilidade engloba as atividades que o pai assume com relação ao filho e com relação a casa. Cada uma dessas temáticas refere-se a uma subcategoria.

A subcategoria tarefas sobre o filho compreende as atividades que o pai assume com relação ao filho. Como tarefas, verificam-se o acompanhamento da saúde do filho (P01, P02 e P04), levantar à noite quando o filho chama (P01 e P03), levar e buscar o filho na escola (P01, P02 e P04; P03 compartilha essa responsabilidade com sua esposa) e cuidar do mesmo quando a mãe não pode (P01, P02, P03 e P04). Verifica-se que um dos pais (P02) alega que nunca faz nada em casa, mas depois ele afirma que sempre lava a 
louça, cozinha e faz as compras. Mesmo que a mãe ainda seja elencada como a principal responsável pelos filhos, verificase que os pais buscam dividir as tarefas:

De madrugada, eu sou o vigilante, é eu quem acorda, porque, como eu ia pro trabalho, ela não poderia, os dois acordar, não adiantou, dai a gente combinou assim, já que é pra acordar alguém, então eu acordo, trato ele, porque muitas vezes era "mamá", ou tirar a fralda, trocar a fralda, então eu fazia isso, pra ela ficar com o sono tranquilo e de dia ela assumia. (P01) A subcategoria tarefas da casa alude as tarefas que os pais realizam com relação à casa e que são de sua responsabilidade. Verifica-se que três (P01, P02 e P04) dos quatro pais são os principais contribuintes para a renda da família, e um dos pais (P03) divide o sustento da casa com a esposa. Além disso, todos os pais afirmam que lavam a louça, e P01 e P02 também fazem as compras. P01 também mencionou que é ele quem prepara o café, arruma a mesa para o café, limpa os vidros e passa aspirador de pó na casa. P04 também comenta que é ele quem dá banho no cachorro, lava o carro e varre a casa. Os quatro pais também alegam que dividem as tarefas da casa, mas, assim como os cuidados do filho, P01, P02 e P04 relatam que a maior parte das tarefas fica com suas esposas. P02 relata essa divisão, que não é rígida, mas é definida:

A gente não tem assim uma tarefa especifica, a única coisa que eu nunca faço, a não ser que a [esposa] não pode é limpar a casa, arrumar as roupas, essas coisas eu nunca faço. Mas do resto, lavar a louça, cozinhar, fazer compras, isso quase sempre é eu que faço.

Constata-se que tanto com relação às tarefas sobre o filho quanto com relação às tarefas da casa, o pai se coloca como ajudante da esposa na maioria das tarefas. Assim, embora busque compartilhar as tarefas, quem fica com grande parte das atividades é a esposa.

A categoria Padrões de relacionamento engloba os padrões de interação entre os membros da família. Subdividese nas seguintes subcategorias, as quais foram embasadas nas divisões realizadas por Marchetto (2012): Relacionamento na família de origem, Relacionamento com a família de origem, Relacionamento com a família do cônjuge, Relacionamento conjugal e Relacionamento parental.

$\mathrm{Na}$ subcategoria relacionamento na família de origem, incluíram-se os padrões de relacionamento mantidos entre os membros das famílias de origem dos cônjuges (Marchetto, 2012). Verifica-se que, nas famílias de origem dos pais, predominam relacionamentos harmônicos (P02 e P04), relacionamentos conflituosos, fundido e conflitual (P01) e também, predomínio de relacionamentos distantes (P03). P04 fala do relacionamento de seus pais, classificado como relacionamento harmônico: "Eles estão há 40 e poucos anos casados, acho que não tem muito o que [risos]. Ah, todo casal deve ter uns, néh, eles não têm nada que, nada que demonstrem... tranquilo o casamento deles". Já no que se refere às famílias de origem das esposas: na família de E02, constata-se o predomínio de relacionamentos distantes; na família de E04 se verificou relacionamentos muito estreitos; nas famílias de E01 e E03 não se observou o predomínio de algum tipo de relacionamento.

A subcategoria relacionamento com a família de origem trata das relações existentes entre cada cônjuge com sua família de origem (Marchetto, 2012). Verifica-se que, no relacionamento dos pais com suas famílias de origem, há um predomínio de relacionamentos harmônicos. Outras formas de relacionamentos foram encontradas, como relacionamento muito estreito, distante, vulnerável e rompimento. Já no que se refere às esposas com suas famílias de origem, constata-se o predomínio de relacionamentos harmônicos em E01 e E03, distantes em E02 e muito estreito em E04. Outras formas de relacionamento também foram evidenciadas como fundido e conflitual e rompimento. Este é evidenciado entre a esposa de P03 e seu pai (pai dela): "A minha mulher não tinha contato com ele, eu nem o conheci. (...) Ela nem quis mais saber dele. $A$ [esposa] que rompeu com ele."

No relacionamento com a família do cônjuge, ressaltamse os relacionamentos entre um cônjuge e a família do seu companheiro (Marchetto, 2012). Todos os pais e suas esposas possuem relacionamentos harmoniosos com a família de origem do cônjuge. Esse relacionamento é evidenciado no seguinte trecho:

O que a gente vai mais é na casa de duas irmãs, essas duas, essas duas famílias a gente, eu conheço bem e a gente se relaciona bem (...). Então a gente sempre vai lá e tal, joga baralho também, gosto também muito do meu concunhado, néh?! A gente se dá muito bem (...) são os que eu mais me dou assim, o resto, até ela mesmo não vai assim, não vai visitar muito. (P01 falando do seu relacionamento com dois cunhados)

A subcategoria relacionamento conjugal refere-se ao relacionamento estabelecido no casal. Os casais P01 e P03 possuem um relacionamento harmonioso, enquanto os casais P02 e P04 possuem um relacionamento muito estreito. P01 fala de seu relacionamento:

Olha, um relacionamento assim bem tranquilo, bem amoroso, a gente se entende bem, a gente graças a Deus fez 17 anos que a gente se conheceu, a gente tem a nossa história, como qualquer namorado, que termina, que volta, aquela coisa toda, e, assim, depois que a gente casou também, nos mudamos algumas vezes, e de modo geral, assim, tem uma e outra questãozinha que a gente briga e tal, mas nada... bem tranquilo assim. Ela, eu sinto que ela me ama bastante, eu também demonstro isso pra ela, é um relacionamento bem estável. (P01 - relacionamento harmonioso)

Além disso, perguntou-se aos pais sobre o seu envolvimento paterno quando o casal está em conflito. Dois pais afirmaram que nada muda (P03 e P04), um deles relata que se envolve mais (P01), e um dos pais negou a existência de conflito entre ele e a esposa (P02).

Evidencia-se como relacionamento parental dois tipos de relacionamentos muito estreitos (E02-F02; P03-F03; P04-F04 e E04-F04) e harmoniosos (P01-F01; E01-F01; P02-F02; e E03-F03), não havendo prevalência de nenhum desses tipos. A fala de P03 exemplifica seu relacionamento com seu filho, classificado como muito estreito: "Acho que se fosse mais [envolvido] ia ser demais até. Eu acho que eu sou muito envolvido. Como eu te disse, ele é a coisa principal". 


\section{Discussão}

A discussão está organizada em três subtemas. Cada um deles corresponde a um objetivo específico, os quais foram mencionados na introdução.

\section{Interação, Disponibilidade e Responsabilidade como Dimensões do Envolvimento Paterno}

No que se refere à interação, embora o pai esteja envolvido nas atividades do cotidiano familiar, como os próprios resultados revelam, a mãe continua sendo a principal responsável pelo cuidado das crianças (Staudt \& Wagner, 2008). Piccinini, Silva, Gonçalves, Lopes e Tudge (2012) também verificaram que os pais se envolvem com os cuidados do filho, embora nem sempre de maneira rotineira. Além disso, diferentemente da afirmação de Balancho (2012), que alega que os homens, em geral, não tomam a iniciativa com relação aos filhos, este estudo revelou que o "novo pai" nem sempre espera a mulher the pedir para fazer algo.

Verifica-se que as vivências anteriores dos pais com crianças possibilitaram aos mesmos sentirem-se competentes nos cuidados dos filhos, e, segundo Pleck (1997), tais habilidades podem contribuir positivamente para um maior envolvimento paterno. $\mathrm{O}$ auxílio da esposa também revela a influência da mulher na relação pai-criança, uma vez que ela pode facilitar ou restringir o envolvimento paterno (Staudt \& Wagner, 2008). A ajuda da esposa, mencionada por três pais, pode ser pensada como um suporte que os pais recebem, aumentando o envolvimento paterno (Lamb, 1997; Pleck, 1997).

A maior demonstração de afeto evidenciada pelos pais está relacionada ao estilo emergente de paternidade (Cabrera \& Bradley, 2012). Sánchez (1996) afirma que as famílias com filhos adotivos apresentam grande escore em afeto e comunicação, mais demonstrado pelas mães do que pelos pais. O diálogo entre pai e filho, tanto para brincar e disciplinar, quanto para falar sobre a adoção, mostrou-se uma forma de vinculação entre os pais e seus filhos(as).

Como o brincar foi a subcategoria com maior frequência de ocorrência, afirma-se que a interação pai-criança é caracterizada pela brincadeira, o que corrobora a literatura (Bossardi, Bueno, \& Vieira, 2015; Dumont \& Paquette, 2012; Lamb, 1997). As atividades mencionadas pelos pais, como andar de bicicleta, ver televisão, jogar bola e ir ao parque, são exemplos de abertura ao mundo, ou seja, atividades que os pais utilizam para incentivar seus filhos a explorar o ambiente, enquanto lhes garantem sua segurança (através do controle/ disciplina) (Paquette, 2004).

Além disso, como afirma Lamb (1997), não basta enfocar apenas quanto tempo o pai passa com a criança, mas devese levar em conta o tempo que ele passa considerando a sua disponibilidade. Com relação a essa dimensão, contata-se que o fato de a mãe ter ou não jornada de trabalho fora de casa não pareceu alterar o envolvimento do pai (Bolze, 2011). O mesmo não se pode afirmar da jornada de trabalho do pai. Ou seja, verifica-se que os pais que têm uma carga horária de trabalho mais flexível (e reduzida) passam mais tempo com seu filho do que o pai que possui uma carga horária de trabalho de 40 horas, o que permite que a esposa tenha mais tempo "livre" para realizar outras atividades. Além disso, quem arruma a criança ou a leva para a escola, por exemplo, também está relacionado com o trabalho do pai, o qual, quando possui tempo, está mais disponível para as atividades que envolvem o cotidiano da criança.

Quanto às responsabilidades assumidas pelos pais, um dos pais afirma que não faz nada, mas enumera algumas das tarefas que são de sua responsabilidade. Essa parece ser uma avaliação crítica por parte do pai. Essa subavaliação difere dos achados de Dubeau, Devault e Paquette (2009), os quais verificaram que o pai supervaloriza seu envolvimento enquanto a mãe costuma subavaliar esse envolvimento.

Embora os pais busquem dividir as tarefas com as mães, a forma como se envolvem com os seus filhos é diferente de como as mães se envolvem com os mesmos. Elas geralmente ficam com mais tarefas de cuidados, enquanto eles geralmente brincam mais com os filhos. Ressalta-se, todavia, que, em se tratando de aspectos psicológicos, para um desenvolvimento infantil saudável, é importante que pais assumam papéis que sejam complementares aos papéis das mães no sistema familiar (Paquette, 2004; Paquette et al., 2009, 2012). Esses diferentes papéis desempenhados por pais e mães, negociados em cada sistema familiar, resultam do contexto cultural no qual estão inseridos, sendo os papéis multidimensionais e complexos (Bolze, 2011), de forma que sua compreensão sistêmica se faz importante (Dubeau et al., 2009).

No que se refere à responsabilidade do sustento financeiro da família, este estudo vai ao encontro dos achados da literatura (Lamb, 1997; Wagner, Predebon, Mosmann, \& Verza, 2005). Ou seja, mesmo que ser provedor da família seja uma tarefa que está cada vez mais sendo compartilhada pelos pais e mães (como em P03), verifica-se, nesta pesquisa, que o homem ainda é o principal responsável pelo sustento econômico da família (P01, P02 e P04). Contudo, mesmo tendo papel importante no sustento financeiro, este estudo reforça os achados de Silva e Piccinini (2007), os quais afirmaram que os pais podem ter uma ampla participação na vida dos seus filhos, não restringindo seu envolvimento ao sustento financeiro, passeios ou brincadeiras. Assim, essa participação do pai pode ser definida, conforme Manfroi et al. (2011), em termos de contribuição direta (interação, estar com a criança) e indireta (provedor, estar acessível e ser responsável pela família).

Os pais se mostram ajudantes da esposa, como também é evidenciado por Andrade et al. (2006), Balancho (2012), Bustamante e Trad (2005) e Nascimento et al. (2013). Além disso, como aponta a literatura (Cabrera \& Bradley, 2012; Simões, Isabel, \& Maroco, 2010; Staudt \& Wagner, 2008), esse pai mais envolvido (estilo emergente de paternidade) resulta da mistura do estilo tradicional de paternidade, no qual o pai ainda é o principal provedor do sustento financeiro da família, com o estilo contemporâneo de paternidade, no qual pai e mãe possuem uma divisão dos cuidados das crianças mais igualitária.

Os resultados encontrados corroboram os estudos que indicam que os pais da atualidade mostram-se mais engajados, responsivos e compartilham tarefas com suas esposas mais do que o esperado em uma visão tradicional de paternidade (Bueno, Vieira, \& Crepaldi, 2015; Cabrera \& Bradley, 2012; Jayakody \& Phuong, 2013). Contudo, 
as mulheres ainda são as principais responsáveis pelas tarefas relacionadas à família e a casa (Jayakody \& Phuong, 2013; Staudt \& Wagner, 2008). Além disso, segundo Lamb (1997), a proporção de tempo de interação, disponibilidade e responsabilidade do pai com seus filhos costuma ser menor que o tempo de interação, disponibilidade e responsabilidade das mães com seus filhos.

Por fim, este estudo não sugere peculiaridades no envolvimento do pai pelo fato de ser adotivo. Além disso, outros fatores devem ser considerados para a compreensão do envolvimento paterno, como os padrões de interação do contexto familiar.

\section{Envolvimento Paterno e Padrões de Interação Familiar}

Constata-se que, nas famílias, é comum existirem diferentes tipos de padrões de relacionamento, os quais definem como cada um participa de cada subsistema e como irá participar (Minuchin, 1982). Verifica-se que, embora sejam diversos os padrões de relacionamento dos participantes e suas esposas nas suas respectivas famílias de origem e com suas respectivas famílias de origem, os padrões de relacionamento com as famílias de origem do cônjuge são predominantemente harmônicos. Assim, nessas famílias, o que compete a cada um, como e quando agir e interagir em cada momento e com cada pessoa, por exemplo, está mais bem definido, o que pode facilitar o envolvimento paterno.

Os estudos sobre a relação entre envolvimento paterno e relacionamento conjugal verificam que o pai se envolve menos, quando há uma relação conjugal problemática (Bolze, 2011; Bossardi, 2011; Cabrera \& Bradley, 2012; Schober, 2012; Simões et al., 2010; Wagner et al., 2005). Entretanto, como os pais relatam apresentar um relacionamento harmonioso ou muito estreito, quando há alguma briga ou discussão, esta parece não afetar seu relacionamento parental. Além disso, o envolvimento paterno elevado pode ser usado como uma resposta para o conflito conjugal (Andolfi, 1996; Gabriel, 2012).

Ressalta-se que uma relação conjugal caracterizada como harmônica não se refere, necessariamente, a uma relação conjugal sem conflitos (Schmidt, 2012). O conflito faz parte de todos os relacionamentos humanos, e pode ser positivo, uma vez que pode servir como oportunidade de transformação aos envolvidos (Bolze, 2011).

Além disso, os pais e as mães evidenciam relacionamentos harmônicos ou muito estreitos com seus filhos. Ressalta-se que, embora seja comum manter um relacionamento muito estreito com os filhos pequenos, é importante estar atento para que esse superenvolvimento não prejudique a emancipação da criança (autonomia). Nos casos de adoção, é possível que os pais busquem fortalecer a vinculação afetiva para "compensar" a falta de vinculação biológica. Entretanto, no estudo de Reppold (2001), constatou-se que os pais adotivos tendem a ser mais indulgentes que os pais biológicos, ou seja, são mais afetivos com os filhos(as), mas, por outro lado, impõem menos limites aos mesmos. Nesse sentido, enfatizase que tanto o afeto quanto a disciplina são importantes para o desenvolvimento da criança (Paquette, 2004).
Assim, de um modo geral, verifica-se que predominam nas famílias estudadas relacionamentos harmônicos ou muito estreitos, ou seja, são famílias que possuem fronteiras nítidas em grande parte de seus subsistemas ou se constata grande dependência emocional, dependência esta que, segundo relato dos pais, não pareceu elevada. Conforme a definição de Wendt e Crepaldi (2008), nas famílias com relacionamentos harmônicos, os membros experienciam união, sustentam sentimentos positivos uns para com os outros e apresentam interesses, atitudes ou valores recíprocos. Além disso, nessas famílias, permite-se que os papéis e as funções de cada membro sejam suficientemente definidos sem interferência indevida de outros membros (Minuchin, 1982), o que possibilitaria um maior envolvimento paterno.

\section{Envolvimento Paterno e Configuração Familiar}

Verificou-se que as famílias dos participantes são compostas por pai, mãe e filho. Essa configuração familiar é ainda a que predomina no Brasil (Instituto Brasileiro de Geografia e Estatística, 2010). Assim como Wagner et al. (2011), constata-se que a configuração familiar não determina nem explica a estrutura da família. Contudo, parte-se do pressuposto de que a configuração familiar pode influenciar o envolvimento paterno e a estrutura familiar. Desse modo, como a família precisa dar conta dos cuidados da prole, quando não há pessoas da família extensa por perto auxiliando nos cuidados das crianças (Bustamante \& Trad, 2005), os pais podem ser mais solicitados, o que de fato acontece, segundo relato dos pais. Embora a configuração familiar seja a de pai, mãe e filho, este filho possui a peculiaridade de ser adotivo. Contudo, no relato dos pais, essa "peculiaridade" não pareceu diferenciá-los dos demais pais.

As famílias dos participantes da pesquisa encontram-se no estágio de famílias com filhos pequenos. Nessa etapa, os adultos precisam cuidar da criança e fazer inúmeros novos ajustes em seu relacionamento, como a forma de divisão das responsabilidades, cuidados da criança e redistribuição de tarefas domésticas (Carter \& McGoldrick, 1995). Esse estágio corresponde à fase de aquisição proposta por Cerveny e Berthoud (2009), que afirmam que essa fase corresponde à aquisição da parentalidade e objetivos comuns, indo desde a união do casal até a entrada dos filhos na adolescência. Assim, como as crianças pequenas necessitam de um maior envolvimento por parte dos pais e das mães principalmente no que se refere aos cuidados básicos (Carter \& McGoldrick, 1995), é esperado encontrar um maior envolvimento dos pais e das mães nesse estágio do ciclo vital.

O "tornar-se pais" no caso da adoção pode acontecer de modo brusco, como se constata com os pais da pesquisa, em que o telefonema avisando que a criança havia chegado foi uma surpresa, pois, eles se prepararam para "a situação (...), mas não para o momento" (sic). Nesse sentido, geralmente há uma maior "correria" (sic) para organizar a casa para a chegada da criança. Esse momento inicial costuma ser estressante, e o apoio da família é fundamental. 


\section{Considerações Finais}

O presente estudo permitiu compreender o envolvimento paterno com filhos adotivos (em termos de interação, disponibilidade e responsabilidade) e que esse envolvimento está inserido e relacionado com a estrutura familiar (descrita através dos padrões de interação familiar, influenciado pela configuração familiar) que o pai apresenta. Assim, concluiuse que os pais adotivos da presente pesquisa, cujos padrões de relacionamento na família são o de relacionamentos harmônicos ou muito estreitos e cuja configuração da família é a de pai, mãe e filho adotivo (com idade pré-escolar), buscam ser pais envolvidos. Ou seja, são pais que brincam, cuidam, conversam, demonstram afeto e têm momentos de lazer com os filhos. Os pais também são participativos na vida de seus filhos quando estão disponíveis, e essa disponibilidade está diretamente relacionada ao trabalho do pai, o qual organiza a rotina da família. Eles também compartilham algumas tarefas e responsabilidades com suas esposas, destacando-se seu papel de provedor. Assim, esses pais se caracterizam pelo que se denomina estilo emergente de paternidade, em que o estilo tradicional e contemporâneo de paternidade se fazem presentes.

O posicionamento epistemológico sistêmico foi útil por permitir uma ampla compreensão do fenômeno. Assim, ressalta-se que não há uma relação linear entre estrutura familiar e envolvimento paterno, ou seja, que, quando há relacionamentos harmônicos ou muito estreitos, o pai será envolvido como descrito acima. $\mathrm{O}$ envolvimento paterno e a estrutura familiar se influenciam mutuamente e são influenciados por inúmeros fatores (como as características, vivências e trabalho do pai, novos modelos de masculinidade, relações conjugais mais democráticas e menos apoio da família extensa), devendo-se sempre contextualizar o fenômeno. Trata-se de uma relação de causalidade circular recursiva, a qual refere-se ao fato do produto ser produtor do próprio processo que o produz (Vasconcellos, 2010).

Em termos metodológicos, os instrumentos mostraramse adequados para atingir aos objetivos, e o estudo poderia ser replicado em outros contextos. Além disso, como os trabalhos iniciais sobre o pai tinham uma maior ênfase no aspecto quantitativo (mensurar número de horas ou atividades do pai para com a criança), este trabalho também contribuiu cientificamente por enfatizar o aspecto qualitativo, ou seja, enfatizar como o pai compreende e significa seu envolvimento e a estrutura familiar. Contudo, seria interessante um estudo que investigasse o mesmo fenômeno sob a abordagem quantitativa (mensurando a frequência e o tempo que realizam atividades com seus filhos), principalmente para verificar se existem correlações significativas entre o envolvimento paterno e a estrutura familiar.

Outra contribuição deste estudo é ter sido realizado apenas com os pais, pois ainda são poucos os estudos que buscam explorar o que o pai tem a dizer sobre seu envolvimento e sua família. Ressalta-se que a maior dificuldade encontrada na pesquisa foi conseguir participantes. Optou-se por não ampliar os critérios de inclusão justamente para se conseguir participantes com características semelhantes. Reforça-se que não se buscou a representatividade do fenômeno, mas o aprofundamento do mesmo.
É possível que os pais que aceitaram participar da pesquisa sejam pais que demonstrem mais interesse no envolvimento com seus filhos do que os que não aceitaram participar. Também é possível que suas respostas apresentem uma desejabilidade social ou que eles tenham se avaliado mais positivamente do que na verdade o são. Uma forma de contornar essa limitação poderia ser realizando filmagens do pai com seus filhos na residência da família. Outra alternativa seria entrevistar também a esposa, visto que ela traria sua percepção sobre o envolvimento do pai e sobre a estrutura familiar. Todavia, ressalta-se que esses pais podem ter demonstrado um maior envolvimento com seus filhos por serem os únicos pais que passam por um "processo de habilitação", o que pode tê-los feito sentirem-se mais "cobrados" para serem pais envolvidos. Além disso, esses pais foram indicados pelas instituições, o que pode ter reforçado o "viés" de "pais perfeitos". Também um deles revelou medo de que pudesse ter ocorrido algum problema com relação à adoção, o que pode ter enfatizado ainda mais os aspectos positivos da paternidade em detrimento dos aspectos negativos.

É possível afirmar que a estrutura familiar constituída de relacionamentos harmônicos ou muito estreitos, na qual o que compete a cada um é uma combinação constante para se ajustar às novas necessidades da família, pode ser um fator potencial de proteção para os membros da família. Isso porque, ao ficar claro o que cada um precisa fazer e como fazer, reduzem-se os estresses e frustrações de expectativas construídas e não realizadas, de cobranças sobre algo não antes estabelecido, auxiliando, dessa forma, na promoção psicossocial de saúde dos membros da família.

Desse modo, pensar o envolvimento paterno considerando a estrutura familiar é um dos grandes desafios ao se estudar os homens da contemporaneidade. Além disso, como o envolvimento paterno é importante para o desenvolvimento da criança, principalmente se esse envolvimento for diferente do envolvimento da mãe, o mesmo pode ser fomentado em programas de intervenção proporcionados por profissionais como psicólogos, não apenas com pais adotivos, mas também com pais biológicos e padrastos.

\section{Referências}

Andolfi, M. (1996). A linguagem do encontro terapêutico. Porto Alegre: Artes Médicas.

Andrade, R. P. de, Costa, N. R. D. A., \& Rossetti-Ferreira, M. C. (2006). Significações de paternidade adotiva: Um estudo de caso. Paidéia, 16(34), 241-252. doi:10.1590/\$0103$863 \times 2006000200012$

Balancho, L. S. (2012). Ser pai, hoje ( $9^{\mathrm{a}}$ ed.). Lisboa: Editorial Presença.

Bardin, L. (1977). Análise de conteúdo. Lisboa: Edições 70.

Bolze, S. D. A. (2011). A relação entre engajamento paterno e conflito conjugal dos pais com crianças de 4 a 6 anos (Dissertação de Mestrado). Universidade Federal de Santa Catarina, Florianópolis, Brasil. 
Bossardi, C. N. (2011). Relação do engajamento parental e relacionamento conjugal no investimento com os filhos (Dissertação de Mestrado). Universidade Federal de Santa Catarina, Florianópolis, Brasil.

Bossardi, C. N., Bueno, R. K., \& Vieira, M. L. (2015). Interação do pai com seus filhos e filhas. In E. R. Goetz \& M. L. Vieira (Eds.), Novo pai: Percursos, desafios e possibilidades (pp. 77-93). Curitiba: Juruá.

Bueno, R. K., Gomes, L. B., \& Crepaldi, M. A. (2015). A importância do pai no desenvolvimento da criança. In E. R. Goetz \& M. L. Vieira (Eds.), Novo pai: Percursos, desafios e possibilidades (pp. 95-107). Curitiba: Juruá.

Bueno, R. K., Vieira, M. L., \& Crepaldi, M. A. (2015). Envolvimento paterno no contexto da adoção. In E. R. Goetz \& M. L. Vieira (Eds.), Novo pai: Percursos, desafios e possibilidades (pp. 45-55). Curitiba: Juruá.

Bustamante, V., \& Trad, L. A. B. (2005). Participação paterna no cuidado de crianças pequenas: Um estudo etnográfico com famílias de camadas populares. Cadernos de Saúde Pública, 21(6), 1865-1874.

Cabrera, N. J., \& Bradley, R. H. (2012). Latino fathers and their children. Child Development Perspectives, 6(3), 232-238. doi:10.1111/j.1750-8606.2012.00249.x

Carter, B., \& McGoldrick, M. (1995). As mudanças no ciclo de vida familiar: Uma estrutura para a terapia familiar. In B. Carter \& M. McGoldrick (Eds.), As mudanças no ciclo de vida familiar: Uma estrutura para a terapia familiar ( $2^{\mathrm{a}}$ ed., pp. 7-29). Porto Alegre: Artmed.

Cerveny, C. M. de O., \& Berthoud, C. M. E. (2009). Ciclo vital da família brasileira. In L. C. Osorio \& M. E. P. do Valle (Eds.), Manual de terapia familiar (p. 25-37). Porto Alegre: Artmed.

Dubeau, D., Devault, A., \& Paquette, D. (2009). L'engagement paternel, un concept aux multiples facettes. In D. Dubeau, A. Devault, \& G. Forget (Eds.), La paternité au XXI sièle (pp. 71-98). Québec, Canada: Les Presses de l'Université Laval.

Dumont, C., \& Paquette, D. (2012). What about the child's tie to the father? A new insight into fathering, father-child attachment, children's socio-emotional development and the activation relationship theory. Early Child Development and Care, 183(3), 1-17. doi:10.1080/03004430.2012.711592

Fagundes, A. J. F. M. (1999). Descrição, definição e registro de comportamento (12 ${ }^{\mathrm{a}}$ ed.). São Paulo: Edicon.

Gabriel, M. R. (2012). Transformações no envolvimento paterno ao longo dos seis primeiros meses do bebê na creche (Dissertação de Mestrado). Universidade Federal do Rio Grande do Sul, Porto Alegre, Brasil.

Ghirardi, M. L. de A. M. (2009). A devolução de crianças adotadas: Ruptura do laço familiar. Revista Brasileira de Medicina: Psicologia em Pediatria, 2(45), 66-70.

Instituto Brasileiro de Geografia e Estatística. (2010). Síntese de indicadores sociais: Uma análise das condições de vida da população brasileira. Retrieved from http://www. ibge.gov.br/home/estatistica/populacao/condicaodevida/ indicadoresminimos/sinteseindicsociais2010/default.shtm

Jayakody, R., \& Phuong, P. T. T. (2013). Social change and fathering: Change or continuity in vietnam? Journal of Family Issues, 34(2), 228-250. doi:10.1177/0192513X12461618
Lamb, M. E. (1997). Fathers and child development: An introductory overview and guide. In The role of the father in child development ( $3^{\mathrm{a}}$ ed., pp. 1-18). New York: John Wiley \& Sons, Inc.

Lamb, M. E., Pleck, J. H., Charnov, E. L., \& Levine, J. A. (1985). Paternal Behavior in Humans. American Zoologist, 25, 883-894.

Manfroi, E. C., Macarini, S. M., \& Vieira, M. L. (2011). Comportamento parental e o papel do pai no desenvolvimento infantil. Revista Brasileira de Crescimento e Desenvolvimento Humano, 21(1), 59-69.

Marchetto, M. V. (2012). A estrutura e a dinâmica de famílias de crianças vítimas de violência (Dissertação de Mestrado). Universidade Federal de Santa Catarina, Florianópolis, Brasil.

McGoldrick, M., \& Gerson, R. (1995). Genetogramas e o ciclo de vida familiar. In B. Carter \& M. McGoldrick (Eds.), As mudanças no ciclo de vida familiar: Uma estrutura para a terapia familiar (2a ed., pp 144-166). Porto Alegre: Artmed.

Minuchin, S. (1982). Famílias: Funcionamento e tratamento. Porto Alegre: Artes Médicas.

Nascimento, A. R. A. do, Vieira, G. T., Mesquita, A. C. R., Gomes, M. M. L. O., Silva, M. C., \& Alves, R. G. S. (2013). Representações sociais de paternidade na revista Pais \& Filhos (1969-2008). Psicologia Argumento, 31(73), 205-213.

Paquette, D. (2004). Theorizing the father-child relationship: Mechanisms and developmental outcomes. Human Development, 47(4), 193-219. doi:10.1159/000078723

Paquette, D., Coyl-shepherd, D. D., \& Newland, L. A. (2012). Fathers and development: New areas for exploration. Early Child Development and Care, 183(6), 735-745. doi: http:// dx.doi.org/10.1080/03004430.2012.723438

Paquette, D., Eugene, M. M., Dubeau, D., \& Gagnon, M.-N. (2009). Les pères ont-ils une influence spécifique sur le développement des enfants? In D. Dubeau, A. Devault, \& G. Forget (Eds.), La paternité au XXI sièle (pp. 99-119). Québec, Canada: Les Presses de l'Université Laval.

Piccinini, C. A., Silva, M. da R., Gonçalves, T. R., Lopes, R. de C. S., \& Tudge, J. (2012). Envolvimento Paterno aos Três Meses de Vida do Bebê. Psicologia: Teoria e Pesquisa, 28(3), 303-314.

Pleck, J. H. (1997). Paternal involvement: Levels, sources, and consequences. In M. E. Lamb (Ed.), The role of the father in child development ( $3^{\mathrm{a}}$ ed., pp. 66-103). New York: John Wiley \& Sons, Inc.

Reppold, C. T. (2001). Estilo parental percebido e adaptaçao psicológica de adolescentes adotados (Dissertaçao de Mestrado). Universidade Federal do Rio Grande do Sul, Porto Alegre, Brasil.

Resolução 196/96 do Conselho Nacional de Saúde, _. (1996). Diretrizes e normas regulamentadoras de pesquisas envolvendo seres humanos. Retrieved from http://www. bioetica.ufrgs.br/res19696.htm

Sampieri, R. H., Collado, C. F., \& Lucio, P. B. (2006). Metodologia de Pesquisa ( $3^{\mathrm{a}}$ ed.). São Paulo: McGraw-Hill.

Sánchez, Y. (1996). Relaciones padres-hijos en familias adoptivas. Anuario de Psicología, 71, 87-105.

Schmidt, B. (2012). Relacionamento conjugal e temperamento de crianças com idade entre quatro e seis anos (Dissertaçao de Mestrado). Universidade Federal de Santa Catarina, Florianópolis, Brasil. 
Schober, P. S. (2012). Paternal child care and relationship quality: A longitudinal analysis of reciprocal associations. Journal of Marriage and Family, 74(2), 281-296. doi:10.1111/j.17413737.2011.00955.x

Silva, M. da R., \& Piccinini, C. A. (2007). Sentimentos sobre a paternidade e o envolvimento: Um estudo qualitativo. Estudos de Psicologia, 24(4), 561-574.

Simões, R., Isabel, L., \& Maroco, J. (2010). Paternal involvement in a group of fathers of elementary school children. Psicologia, Saúde \& Doenças, 11(2), 339-356.

Staudt, A. C. P., \& Wagner, A. (2008). Paternidade em tempos de mudança. Psicologia: Teoria e Prática, 10(1), 174-185.

Vasconcellos, M. J. E. de. (2010). Pensamento Sistêmico: O novo paradigma da ciência ( $9^{\mathrm{a}}$ ed.). Campinas: Papirus.

Vieira, M. L., Bossardi, C. N., Gomes, L. B., Bolze, S. D. A., Crepaldi, M. A., \& Piccinini, C. A. (2014). Paternidade no Brasil: Revisão sistemática de artigos empíricos. Arquivos Brasileiros de Psicologia, 66(2), 36-52.
Vieira, M. L., Crepaldi, M. A., Bossardi, C. N., Gomes, L. B., Bolze, S. D. A., \& Piccinini, C. (2013). Paternity in the Brazilian context. In M. L. Seidl-de-Moura (Ed.), Parenting in South American and African Contexts (pp. 35-64). InTech. doi: $10.5772 / 57520$

Wagner, A., Predebon, J., Mosmann, C., \& Verza, F. (2005). Compartilhar tarefas? Papéis e funções de pai e mãe na família contemporânea. Psicologia: Teoria e Pesquisa, 21(2), 181-186.

Wagner, A., Tronco, C., \& Armani, A. B. (2011). Os desafios da família contemporânea. In A. Wagner (Ed.), Desafios psicossociais da família contemporânea: Pesquisas e reflexões (p. 19-35). Porto Alegre: Artmed.

Weber, L. N. D. (2003). Aspectos psicológicos da adoção (2a ed.). Curitiba: Juruá.

Wendt, N. C. (2006). Fatores de risco e de proteção para o desenvolvimento da criança durante a transição para a parentalidade (Dissertação de Mestrado). Universidade Federal de Santa Catarina, Florianópolis, Brasil.

Wendt, N. C., \& Crepaldi, M. A. (2008). A utilização do genograma como instrumento de coleta de dados na pesquisa qualitativa. Psicologia: Reflexão e Crítica, 21(2), 302-310.

Recebido em 28.02.2014

Primeira decisão editorial em 14.03.2016

Versão final em 25.04.2016

Aceito em 25.04.2016 